\title{
PERFORMED TREATMENT IN WOMEN WITH BREAST CANCER IN A SECONDARY PUBLIC HOSPITAL IN FEDERAL DISTRICT
}

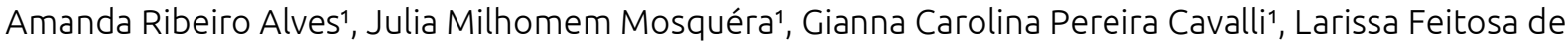
Albuquerque Lima Ramos ${ }^{1}$, Flavio Lucio Vasconcelos²

'Centro Universitário de Brasília - Brasília (DF), Brazil.

'Mastologia do Hospital Regional de Santa Maria - Brasília (DF), Brazil.

Objective: To evaluate treatments performed in women with malignant breast cancer treated at the mastology service of a public secondary-level hospital. Method: A cross-sectional study with women diagnosed with breast cancer from 2012 to 2019. Treatments evaluated were surgery, chemotherapy, radiotherapy, and hormone therapy. Data were analyzed using the SPSS software (vision 26.0), considering p<0.05 as significant. Results: We evaluated the data of 227 patients with tumors in stages I (10.1\%), II (35.2\%), III (26.9\%), and IV (12.78\%), with 55.5\% of them between the ages of 40 and 60 years. Mastectomy was performed in $61.7 \%$ of the patients, with $84.6 \%$ not undergoing immediate reconstruction, while $12.8 \%$ undergoing late reconstruction. Techniques used were large dorsal muscle flap with prosthesis (29.4\%), rectus abdominis muscle (26.5\%), and only prosthesis (23.5\%). Patients aged $<40$ years required mastectomy in detriment of the conservative approach $(\mathrm{p}=0.04)$. Forty-five percent of women underwent immediate axillary lymphadenectomy and $11.6 \%$ after positive sentinel lymph node, with $76.1 \%$ having one to three affected lymph nodes. Chemotherapy was performed in $67.0 \%$ of the patients, the majority being neoadjuvant (50.3\%). Patients aged $<60$ years were more frequently submitted to chemotherapy $(\mathrm{p}<0.001)$. Radiotherapy was performed in $56.8 \%$ of the patients, with those aged $<40$ years found significant ( $\mathrm{p}=0.005$ ). Hormone therapy was performed in $59.0 \%$ of the patients. The mean time between diagnosis and the start of chemotherapy was $134.8 \pm 126.5$ days, and the average gap between treatments (chemotherapy/radiotherapy) was 188.2 \pm 204.6 days. Conclusion: Mastectomy was the most performed treatment, with a small part of the patients obtaining breast reconstruction. Most patients needed some type of complementary therapy, especially the younger ones. The average time between diagnosis and treatment was longer than that recommended by current legislation. Awareness measures and better access to women with breast complaints should be emphasized, especially in younger women.

Keywords: Breast Neoplasms; Therapeutics; Medical Oncology. 